\title{
A Novel Design, Implementation and Testing of stress monitoring with IOT Technology
}

\author{
Kumara K R \\ Assistant Professor \\ Department of Electronics and Communication Engineering \\ Sai Vidya Institute of Technology \\ Rajanukunte, Banglore-560064, Karnataka, INDIA \\ E-mail: kumara.kr@saividya.ac.in \\ Suhasini R, Shubha R, Varshini B S, Navya B R \\ Department of Electronics and Communication Engineering \\ Sai Vidya Institute of Technology \\ Rajanukunte, Banglore-560064, Karnataka,INDIA
}

\begin{abstract}
$\underline{\text { ABSTRACT }}$
This proposed paper is on the recognition of stress applied on the foot on the daily basis by people. This type of stress is affected to the people who stand a lot and repeatedly performs the same work. The cause of this usually varicose veins and growth of calcaneum bone known as calcaneum spur. The objective of this project is analyses of foot stress applied to the hind foot by the people suffering from these disorders. This proposed paper is of monitoring of stress may help users to better understand the stress patterns and also supply the physiotherapist with valid data for arbitrament.
\end{abstract}

\section{Keywords : IoT}

\section{INTRODUCTION}

From the past few years, the word stress has become more common. The stress is the way in which the body responds to any kind of demand or threat. The body reacts to changes with physical, mental and emotional responses. The stress is also classified into these types such as physical, mental and emotional stress. Our paper mainly focuses on the physical stress or foot stress. The physical stress caused by the body and its effects on foot. The amount of physical stress the foot is bearing. The foot is one of the shock absorber and stress bearer in the body, which is the terminal part of the body. This vigorous structure is divided into different parts. They are hindfoot, midfoot, and forefoot.

The foot is the least cared part of the body. Foot stress is mostly found in the people who stand for a prolonged period of time. By this, the pain in the foot will be more than the person who walks more. This type of effects is mostly found in people with professions like teachers, conductors, and athletes. This foot stress causes many issues. After aging people take care of this which is too late and leads to many disorders.

There are many disorders like varicose veins, calcaneum spur, and stress fracture. Varicose vein the blood clot in the nerve in which the flow of direction of blood is only one direction and it does not pump back to the heart. This is one of the major disorders found mostly in women and people who stand a lot. Calcaneum spur is the extra growth of the blood in the hindfoot. The stress fracture is caused by doing things repetitively. Performing an activity repeatedly and when a lot of stress is applied to the foot then it is classified as the stress fracture. As well as we all know leg disorders are quite common to the aged people, obesity is also one of the reasons for this. Thus, the amount of weight foot bearing is more. Thus, they can get leg disorders due to stress on feet at early age.

Hence the proposed project helps the subject to identify the amount of foot stress applied on foot and to take prior actions and preventing from major disorders.

\section{RELATEDWORK}

Identification of health-related problems using gait patients and using certain sensors such as EMG, floor sensors, an accelerometer attached to the shoe of the subject along with embedded IoT sensors and gathering data has become many studies over 
the decade. The post-study shows that abnormal gait detection in stroke patients using wireless for a system [1].In [2], there are several research projects with mobile ECG recording using Internet solutions, cellular phones, Bluetooth technology and wireless local area networks, wireless and WLAN stress networks.

In [3], a wireless diagnosis system integrating digital telemetry, a homecare station is developed. A gait monitoring system based on a mobile platform which transmits abnormal walking identified in a work unit is developed in [4].In [5], a smartphone based gait division system that can alert the users about the abnormal walk.

In this paper, we propose an IoT based systems to detect the foot stress in both affected and nonaffected and send the message to the patient as well as the doctor too.To overcome the drawbacks from the above-mentioned researches, in this paper, we propose a model and design which help in identifying the stress and helps both the doctor and the patient. Our system is to yield the stress applied by the patient and take the precautions to the best of our knowledge, our systems are the first model which assists both patient and the doctor to know the amount of stress applied for both affected and unaffected persons.

\section{METHODOLOGY:}

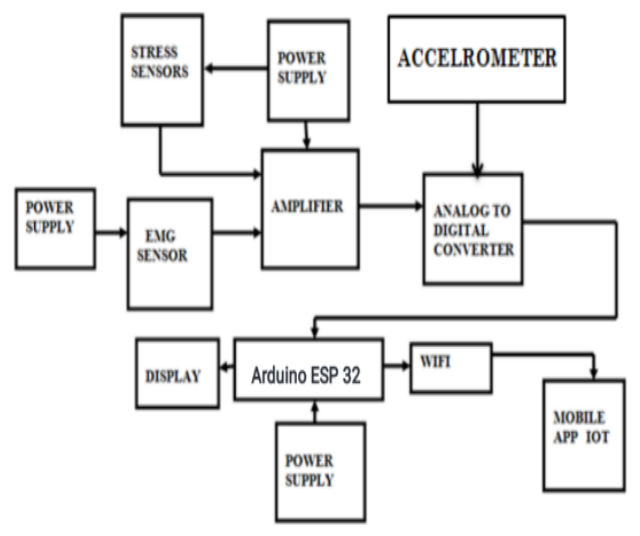

Fig1: Proposed block diagram

The proposed block diagram consists of EMG Sensor, Accelerometer, ADC and Arduino. The EMG sensor is used to analyze the muscle activity and the obtained sensor values are given to the ADC which is then given to Arduino and displaying it through a graph. The Accelerometer is used to obtain the tilt position of the foot.

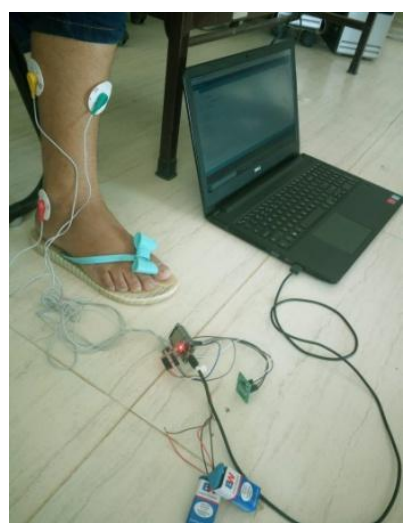

Fig 2: The Circuit connection for the proposed block diagram.

Initially the muscle activity is known from the EMG sensor. The noted muscle activity is converted from analog to digital signal. The converted digital signal is then given to the Arduino. The Arduino is an open-source physical computing platform based on simple I/O pins and it consists of the WiFi module which helps in transferring the analog signal to the smart phone. The transferred didgital signal is processed to analog signal and is displayed on the smartphone through the application developed on the IoT Technology, i.e. Blynk application. The accelerometer is used to obtain the tilt position of the leg. The accelerometer gives the axis for each tilt position. The obtained digital data is then exported to CSV file which converts to analog data which is used for clustering.

The Fig 3 represents the visualization of the graph and the variation in the tilt position of the leg. The obtained datasets is collected over period of time and is analyzed for clustering.

The probability of our proposed foot stress monitoring system is dependent on existing wireless communication module and the application to provide a low-cost solution with maximum freedom for user and doctor.

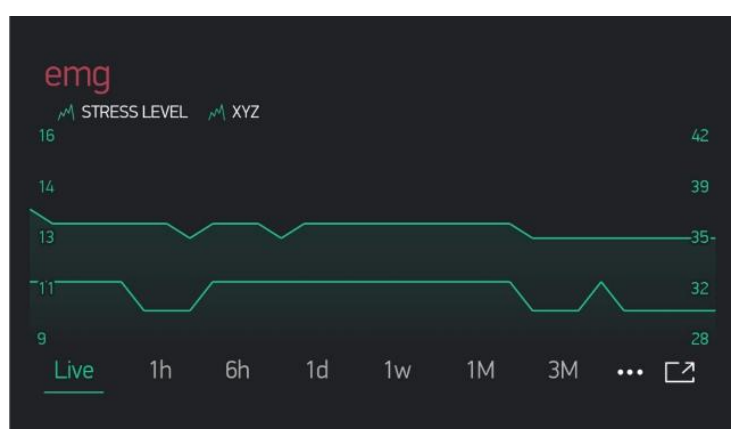

Fig3: Shows stress graph 


\section{IMPLEMENTATION AND TESTING}

To evaluate the proposed prototype model we have evaluated the prototype with extensive experiments. The collected data is clustered. This process helps in obtaining the mean value from the collected value which helps in analyzing the collected data.

\section{CONCLUSION}

In this paper, we presented a wireless system to analyze the foot stress using the sensors and model. This proposed system can predict foot stress. We presented preliminary from the patient using the model and showed that the data can analyze the foot stress.

Our future approach is to obtain the stress analyzing by considering different COP. By changing COP the obtained data can be analyzed for different COP.

\section{REFERENCES}

[1]Majumder, A.J.A., ElSaadany, Y., ElSaadany, M., Ucci, D.R. and Rahman, F., 2017, March. A wireless iot system towards gait detection in stroke patients. In 2017 IEEE International Conference on Pervasive Computing and Communications Workshops (PerCom Workshops) (pp. 449-454). IEEE.

[2] Aminian, M. and Naji, H.R., 2013. A hospital healthcare monitoring system using wireless sensor networks. J. Health Med. Inform, 4(02), p.121.

[3] Nam, Y.H., Halm, Z., Chee, Y.J. and Park, K.S., 1998, October. Development of remote diagnosis system integrating digital telemetry for medicine. In Proceedings of the 20th Annual International Conference of the IEEE Engineering in Medicine and Biology Society. Vol. 20 Biomedical Engineering Towards the Year 2000 and Beyond (Cat. No. 98CH36286)(Vol. 3, pp. 1170-1173). IEEE.

[4] Wen, C., Yeh, M.F., Chang, K.C. and Lee, R.G., 2008. Real-time ECG telemonitoring system design with mobile phone platform. Measurement, 41(4), pp.463-470.

[5] Majumder, A.J.A., Rahman, F., Zerin, I., Ebel Jr, W. and Ahamed, S.I., 2013, March. iPrevention: Towards a novel real-time smartphone-based fall prevention system. In Proceedings of the 28th

\section{Annual ACM Symposium on Applied Computing(pp. 513-518). ACM.}

[6] Majumder, A.J.A., Zerin, I., Uddin, M., Ahamed, S.I. and Smith, R.O., 2013, October. SmartPrediction: A real-time smartphone-based fall risk prediction and prevention system. In Proceedings of the 2013 Research in Adaptive and Convergent Systems (pp. 434-439). ACM.

[7] Ko, D.Y. and Lee, H.S., 2013. The changes of COP and foot pressure after one hour's walking wearing high-heeled and flat shoes. Journal of physical therapy science, 25(10), pp.1309-1312.

[8] Kim, M.K. and Lee, Y.S., 2013. Kinematic analysis of the lower extremities of subjects with flat feet at different gait speeds. Journal of physical therapy science, 25(5), pp.531-533.

[9] Lee, J.E., Park, G.H., Lee, Y.S. and Kim, M.K., 2013. A comparison of muscle activities in the lower extremity between flat and normal feet during one-leg standing. Journal of physical therapy science, 25(9), pp.1059-1061.

[10] Muro-De-La-Herran, A., Garcia-Zapirain, B. and Mendez-Zorrilla, A., 2014. Gait analysis methods: An overview of wearable and nonwearable systems, highlighting clinical applications. Sensors, 14(2), pp.3362-3394. 